A. S. Kucher,

Senior Lecturer;

ORCID: 0000-0001-5478-9463

A. V. Paulava, $\mathrm{PhD}$ of Technical Sciences, Associate Professor, ORCID: 0000-0003-3216-9989

V. V. Maskva, $\mathrm{PhD}$ of Technical Sciences, ORCID: 0000-0002-3754-607X

Yanka Kupala State University of Grodno

Scientific and practical centre for foodstuffs of the National academy of Sciences of Belarus, Minsk, Belarus

\title{
TRENDS IN THE TECHNOLOGY OF COOKING PRODUCTS CATERING
}

The article describes modern cooking technologies for culinary products in the field of catering and their advantages over traditional cooking methods.

Keywords: bain-marie, WOK, deglazing, flambe, confit.

Relevance of the research topic. Gastronomic art in Belarus and the world as a whole has achieved significant success over the past decade. This is manifested in the use of new (non-traditional) types of food products, modern types of equipment and technologies; the development of unique products with a unique taste and appearance, design. First of all, the creation of a new culinary product begins with the use of new culinary technologies.

Formulation of the problem. The paramount task is the introduction of energy-saving technologies, improving the sanitary and hygienic conditions at the workplace, improving the quality of finished products. The focus is on new, dynamic operations that at the same time meet the requirements of sustainable development and thrift. All these tasks are equally faced by the restaurant industry.

Analysis of recent research and publications. Scientific literature and regulatory information on modern technologies for the preparation of culinary products in public catering is analyzed.

Presenting main material. Cooking in a water bath (Bain-marie - French) the process of cooking food in a device for heating substances, when the required temperature is not more than $100{ }^{\circ} \mathrm{C}$ at normal atmospheric pressure. This device is a 
«double pan» mounted on a stove. Water is poured into the lower one, and the product is placed in the upper one. Legends claim that a certain Miriam who was engaged in alchemy invented it. Miriam persistently searched for a philosopher's stone, but did not find. But she found a great way to slowly heat up - a water bath. As a result of the experiments, she found out that water can be an excellent insulator for high temperature, because it has the ability to absorb thermal energy. A water bath is indispensable if you need to very slowly and delicately heat or melt some ingredient. In a water bath, for example, chocolate is heated.

Cooking in a WOK. The wok pan has a round shape, a convex bottom, high and thin walls. It is made of cast iron or carbon steel and has one wooden handle. In China, they are often cooked on special burners, in the center of which there is a semicircular recess. With its help, the WOK-pan acquires stability, and a powerful flame quickly and evenly heats the walls. A frying pan in a WOK is mainly used for quick frying roast, but also possible in it: stew meat and vegetables, covered with a lid; use for deep-frying; use as a double boiler using a special grill; cook soups.

Saute- a method of culinary processing of food products, a distinctive feature of which is the rapid frying of food raw materials on a fairly high fire with minimal use of fat. The word «sauté» itself has French roots - comes from the word sauter- to jump (association with the squawking and «bouncing» food in the pan). Cooked dishes are traditionally served with sauces based on the juices that the product emits during heat treatment. For cooking sauté, it is recommended to choose products that differ in a rather delicate texture. From meat, ribs, fillets and parts of the back leg (pork, veal, lamb, beef) are well suited for these purposes. It is good in the form of fried breasts of domestic and wild birds, fish with elastic or moderately elastic flesh (for example, cod, pollock, salmon, trout). Immediately before cooking, pieces of food are dried with dry paper towels, after which seasonings are added to the food raw materials to achieve the optimal taste. In some formulations, the next step is to roll the product into flour, the excess of which is shaken off. This allows you to get a delicious golden crust, which is especially true for the pale surfaces of some varieties of meat and fish.

Deglazing is a special culinary technique, thanks to which it is possible to prepare a sauce from a thick dark mass, which, as a rule, is formed after frying meat in oil or fat. To make a sauce of this mass, simply add liquid to it. It can be wine, water, broth, cream and other ingredients. When the liquid begins to boil, it is necessary to scrape off the mass from the walls and the bottom, bringing to uniformity. Then the excess liquid is drained, and what is left can be used as a ready-made sauce or as a basis for it.

Flambe - cooking on a natural fire. Ignition is most often the last step in cooking, this can be done in the presence of a guest in the restaurant hall. Sometimes 
kindling is one of the intermediate stages of cooking, for example, when cooking soups from mashed potatoes from crayfish and seafood (biscuit). In the first case, the ignition becomes a kind of spectacle, first of all, an element of the commercial attractiveness of the restaurant, in the second it is used to create a fragrant bouquet for dishes.

Regardless of when this method is used, caution and safety rules must be observed. If you add alcohol directly to the hot pan from the bottle (it does not matter if it is equipped with a geyser or not), then the flame that occurs when the alcohol comes in contact with the hot pan rushes to the bottle with alcohol and causes an explosion. Any type of alcoholic beverage used for ignition, regardless of its strength, should be poured from small vessels with a wide nose.

Barbecue is frying food on pre-heated and greased rods over a strong heat source (coal, gas or firewood). When using solid fuel (charcoal or briquettes for barbecue), the flame and smoke must disappear before the products are placed on the rods, otherwise the dish will turn out with an unpleasant aftertaste. The barbecue boiler is equipped with a domed lid with two ventilation holes. This creates a baking effect as in a combi oven, but with the aroma of smoke. To get an extra flavor, you can sprinkle the coals with rosemary or fennel stalks.

Before cooking, some products, such as venison kebabs, beef steaks, escalopes, natural veal cutlets or chicken, must be marinated, and during cooking, brush or a bunch of thyme or rosemary with olive oil, herbs and spices. You can use green lemon oil for lubrication. Some products (for example, pork ribs) are generously lubricated with glaze on both sides during cooking.

Confi technology. Confi cooking is done at a relatively low temperature (70 to $130^{\circ} \mathrm{C}$ ) in one's own fat; although fat does not burn, this means that no carcinogens are formed during cooking. The taste and texture vary depending on the purpose of the dish. As a rule, for the preparation of confit, duck or goose meat is used, as well as other types of fatty meat (pork, lamb). Pre-marinated meat or poultry is slowly stewed in their own fat until softened, that is, languishing. In France, only a duck or goose dish is considered a real confection; any other meat processed using the fat from these birds is considered «cooked as confit».

Processing in a flame of a gas burner. The flame of a gas burner is used in home cooking to singe birds. But thanks to the creation of special gas burners (including very miniature ones), it became possible to apply a picture to the surface of the finished culinary products in order to create a thin crispy caramel crust on the surface (alternatively using a grill). This method allows you to get real clarity.

Drying fruits, vegetables. This processing method is used in restaurant practice not for canning products, but for obtaining chips. Chips are very thin slices of 
vegetables (eggplant, artichoke, zucchini. .. ) and fruits (orange, grapefruit, apple. . . ), dried in the oven to a crisp state. The fruit is pre-cooked in sugar syrup, and then dried in a double boiler at $100^{\circ} \mathrm{C}$. Chips are used to decorate restaurant dishes. In addition to decorative, they perform an important function in the taste of the dish, for example, create a contrast with the delicate taste of mousses and crispy chips.

Bake, this method is known in domestic technology only as an auxiliary. Used in the heat treatment of onions, carrots, root crops for cooking broths. Recently, this method has become fashionable and is often used in the preparation of fish and seafood dishes. The prepared piece of fish is placed in a hot pan and, holding it a little on one side, is turned on the other, and then served almost immediately on the table. As a result, a fragrant crisp forms, and inside the fish remains tender, juicy and almost raw. Fish cooked in this way, less often meat, becomes the main ingredient in the now popular «warm salads» with various kinds of leafy vegetables and fruits. Baked fish, when served, is specially broken or cut into slices so that this unusual contrast is visible.

Conclusions. Based on the analyzed literature, we studied modern technologies for the preparation of products in public catering. An opinion has been formed that all types of cooking technologies are slowly entering the work of public catering facilities in order to improve the taste of dishes and reduce losses during cooking.

\section{REFERENCES}

1. Dolgopolova S. V. New culinary technologies. Restaurant sheets, 2015. 272 p.

2. Sharokhina S. V.,Gorokhovitskaya T. N. Innovations in the field of public catering, as a factor of strategic management. Internet-journal «ScienceofScience». 2017. Vol. 9. Is. 5. P. 5-17.

3. Sovremennye napravleniia prigotovleniia i oformleniia kulinarnoi produktsi i [Modern cooking directions and registration of culinary products]. (n. d.) journalpro. $\quad r u$. Retrievedfromhttp://journalpro. ru/articles/sovremennyenapravleniya-prigotovleniya-i-oformleniya-kulinarnoy-produktsii/ [inRussian]. 